\section{Commentary: Different location, same challenges}

\author{
John S. Ikonomidis, $\mathrm{MD}, \mathrm{PhD}$
}

I read with interest the excellent review in this issue of the Journal by Fudulu and Angelini ${ }^{1}$ regarding the academic surgeon model in the United Kingdom. This carefully constructed review succinctly laid out the status of academic cardiac surgery primarily from the clinical research perspective and summarized the important obstacles that UK surgeons must tackle to have successful clinical and research careers. The overarching conclusion, I surmised, is that a change in geographic location, at least in this instance, does not change the fundamental issues surgeons face, which can be itemized as economic and clinical pressures, difficulty in obtaining funding, and the changing pattern of the preferences and goals of the surgeons themselves.

It seems evident from the UK review that economic and clinical requirements have driven surgeon productivity to the point that a specific academic surgeon training track was introduced to encourage concurrent development of clinical and investigative skills in select individuals willing to devote the time to academic surgical practice. This format is one that we could adopt to a greater extent than is currently being used in the United States. Compensation for academic work is scarce in the UK. Surgical units in the UK may consider adding an academic incentive structure to their surgeon reimbursement.

Additional challenges are endemic, not the least of which is the requirement for funding. The success rates of grant applications submitted to UK funding agencies run around $20 \%$ to $25 \%$, which is superior to success rates in the United States. Nevertheless, these odds do not favor

\footnotetext{
From the Division of Cardiothoracic Surgery, University of North Carolina at Chapel Hill, Chapel Hill, NC

Supported by NIH/NHLBI grants 2R01HL102121 and 1R21HL148363.

Disclosures: The author reported no conflicts of interest.

The Journal policy requires editors and reviewers to disclose conflicts of interest and to decline handling or reviewing manuscripts for which they may have a conflict of interest. The editors and reviewers of this article have no conflicts of interest.

Received for publication July 20, 2020; revisions received July 20, 2020; accepted for publication July 21, 2020; available ahead of print July 24, 2020.

Address for reprints: John S. Ikonomidis, MD, PhD, Division of Cardiothoracic Surgery, University of North Carolina at Chapel Hill, 3034 Burnett Womack Building, 160 Dental Circle, Chapel Hill, NC 27599-7065 (E-mail: john_ikonomidis@med. unc.edu).

J Thorac Cardiovasc Surg 2021;162:1595

$0022-5223 / \$ 36.00$

Copyright (c) 2020 by The American Association for Thoracic Surgery

https://doi.org/10.1016/j.jtcvs.2020.07.062
}

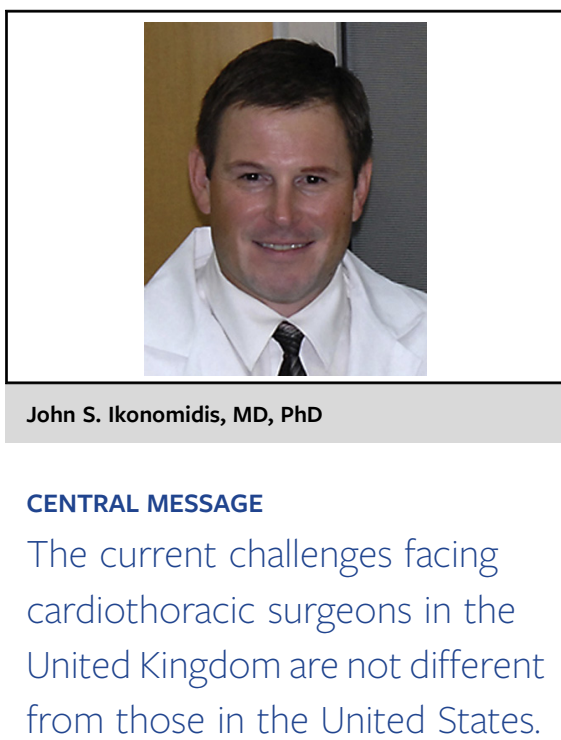

surgeons in the United Kingdom, who are forced to compete with nonphysician scientists, who arguably have more time to conceptualize, craft, and polish their grant applications. Further, it is likely that funding success rates will fall, especially in the relatively acute timeline, as the COVID-19 pandemic cripples the world economy and forces redistribution of funds, probably away from research programs.

Finally, individual surgeon preferences drive much of the probability of success in research. The willingness to accept a lower salary and devote "after hours" time during the evenings and weekends to developing a research career is becoming less and less palatable for young surgeons, many of whom are seeking a better lifestyle. The ability to perform a large number of operations while managing to publish prolifically in the medical literature, give presentations regularly at meetings, and maintain a funded research effort is not an innate skill. Although I would agree that financial support and providing protected research time for surgeons is very important, there is an intrinsic quality that certain individuals have that allows them to conduct a busy surgical practice while also allowing academic productivity. It is an ability that is spawned from discipline, drive, passion, and exquisite time management skills. It remains paramount that those surgeons possessing these characteristics be supported to the fullest extent possible, regardless of location.

\section{Reference}

1. Fudulu DP, Angelini GD. Flourish or perish: the UK academic surgeon model J Thorac Cardiovasc Surg. 2021;162:1590-4. 